刘静如, 郭可馨, 谌亚, 李晗, 张丽, 游成铭, 徐振锋, 谭波.亚热带森林调落叶分解过程土壤节肢动物群落的变化特征.生态学报, 2021,41(7)： 2770-2782.

Liu J R, Guo K X, Sheng Y, Li H, Zhang L, You C M, Xu Z F, Tan B.Changes of soil arthropod community during litter decomposition in a subtropical forest. Acta Ecologica Sinica, 2021,41(7):2770-2782.

\title{
亚热带森林调落叶分解过程土壤节肢动物群落的变化 特征
}

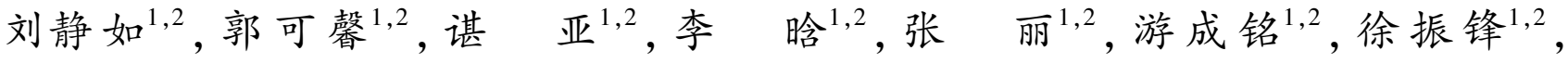
谭 波 ${ }^{1,2, *}$

1 四川农业大学生态林业研究所, 长江上游林业生态工程四川省重点实验室,水土保持与荒漠化防治省级重点实验室, 成都 611130 2 长江上游森林资源保育与生态安全国家林业和草原局重点实验室, 成都 611130

摘要: 土壤动物群落结构和多样性可能随调落物分解进程和基质质量的变化不断改变。为了解亚热带森林调落叶分解过程中 土壤节肢动物群落变化特征, 以四川盆地亚热带森林麻栋 ( Quercus acutissima) 和柳杉 (Cryptomeria fortunei) 调落叶为对象, 于 2011-2015 年采用分解袋法研究了 2 种调落叶分解过程中土壤节肢动物组成、结构和多样性动态变化。整个研究期间,柳杉和 麻柇调落叶分解袋中共捕获土壤节肢动物 3855 只,分属于 16 目 51 科,且均以等节跳科和棘跳科为优势类群; 麻柇凋落叶中土 壤节肢动物的个体密度随分解进程呈现增加趋势, 在分解的 1079 天达最高值后降低, 而柳杉调落叶则在分解的 156 天急剧增 加后快速降低, 2 种调落叶中土壤节肢动物类群数量具有相似的动态变化过程; 2 种调落叶中土壤节肢动物总体以菌食性数量 比例最高, 腐食性最低, 且随调落叶分解进程, 植食性土壤节肢动物占比明显下降, 菌食性则上升; 非度量多维尺度 (NMDS) 分 析显示, 2 种调落叶中土壤节肢动物群落组成具有显著差异, 聚类分析表明, 2 种调落叶土壤节肢动物群落结构相似性随分解进 程不断降低。亚热带森林调落叶分解过程中土壤节肢动物群落组成、结构和多样性受调落叶类型影响。

关键词: 土壤节肢动物;功能类群; 调落物类型; 调落物分解;亚热带森林

\section{Changes of soil arthropod community during litter decomposition in a subtropical forest}

LIU Jingru ${ }^{1,2}$, GUO Kexin ${ }^{1,2}$, SHENG Ya ${ }^{1,2}$, LI Han ${ }^{1,2}$, ZHANG $\mathrm{Li}^{1,2}$, YOU Chengmin ${ }^{1,2}$, XU Zhenfeng ${ }^{1,2}$, TAN Bo ${ }^{1,2, *}$

1 Institute of Ecology \& Forestry, Sichuan Agricultural University; Sichuan Province Key Laboratory of Ecological Forestry Engineering on the Upper Reaches of the Yangtze River; Provincial Key Laboratory of soil and water conservation and desertification control, Chengdu 611130, China

2 National Forestry and Grassland Administration Key Laboratory of Forest Resources Conservation and Ecological Safety on the Upper Reaches of the Yangtze River, Chengdu 611130, China

\begin{abstract}
Soil fauna are crucial decomposers in terrestrial ecosystem. The structure and diversity of soil fauna may vary with changes in decompsition stages and litter quality during litter decomposition, but how the compositon and structure of soil arthropod vary during litter decompostion in subtropical forests remain poorly understood. In this study, we conducted a fouryear litter decomposition experiment $(2011-2015)$ to explore the compositon, structure and diversity of soil arthropod during litter decomposition. Two dominant tree species with contrasting leaf traits (coniferous vs. broadleaf) were used for

基金项目:国家自然科学基金项目 (31870602，31700542); 四川省杰出青年科技人才项目 (2020JDJQ0052); 四川农业大学科研兴趣培养项目 (2019267)

收稿日期: 2020-04-20; 网络出版日期:2021-01-28

* 通讯作者 Corresponding author.E-mail: bobotan1984@163.com
\end{abstract}


field incubation in a subtropical forest of Sichuan Basin, southwestern China. Fresh senesced litter was collected using $1 \mathrm{~m} \times$ $1 \mathrm{~m}$ litter traps in our study site between September and October 2011. The litter contained a coniferous species (Cryptomeria fortunei) and a broadleaf species (Quercus acutissima). The litter samples were air-dried for 2 weeks at $25{ }^{\circ} \mathrm{C}$ and $10 \pm 0.05 \mathrm{~g}$ was placed in $20 \mathrm{~cm} \times 20 \mathrm{~cm}$ nylon litterbags. A total of 130 litterbags ( 11 sampling times $\times 5$ plots $\times 2$ tree speices+20 spare litterbags) were carefully placed on the forest floor in late November 2011. A total of 11 sampling events were performed during our four-year litter decomposition study. Throughout the four years of decomposition, 3855 individuals and 51 families of soil arthropod were extracted from the litterbags. According to the individual proportion and composition of the taxa, Isotomidae and Onychiuriclae were the two numerically dominant taxa regardless of tree species during the decompositon. The individual density of the soil arthropod in the broadleaf litter showed an increasing trend with the decomposiotn proceeded and reached the maximum level at 1079 days of decomposition, and that in the coniferous litter increased to the maximum level at 156 days of decomposition and then rapidly decreased. The family richness of the soil arthropod in both the broadleaf and coniferous litter had a similar dynamic during litter decompostion. The fungivorous and saprophyte soil arthropod were the highest and least proportion of funcational groups of soil arthropod during the decompostion, respectively. As the decompsition proceeded, the proportion of the phytophaga soil arthropod decreased and that of the fungivorous soil arthropod increased. The NMDS analysis showed that the composition of soil arthropod community had sigificant difference between the broadleaf and coniferous litter. The cluster analysis indicated that the similarityof soil arthropod community structure between the broadleaf and coniferous litter continued decrease during the study. The results suggest that the composition, structure and diversity of soil arthropd are affected by litter type during litter decomposition in subtropical forests.

Key Words : soil arthropods ; functional group; litter types; litter decomposition; subtropical forest

调落物分解是森林生态系统物质循环和能量流动的核心环节 ${ }^{[1]}$ 。已有的研究证实, 森林生态系统所有 植物性养分的再循环过程均通过土壤碎屑食物链能量流动渠道 (细菌或真菌) 进行 ${ }^{[2]}$ 。尽管气候和调落物基 质质量是调控全球和区域尺度上调落物分解速率的主要因子, 但是土壤动物群落是构成调落物分解速率变异 的重要生物因素 ${ }^{[3-4]}$ 。土壤动物群落不仅能通过吞噬、破碎、混合等直接作用改变调落物形态和表面积加速 调落物养分流动速率 ${ }^{[5]}$, 而且能通过选择性取食控制土壤微生物丰度、活性和多样性以及繁殖体接种传播间 接影响土壤物质循环的速率和方向以及整个土壤养分库营养效率 ${ }^{[6-7]}$ 。因此, 研究土壤动物群落及其对调落 物分解的作用对深人认识地表生态系统物质循环至关重要。

调落物分解是一个连续变化的过程, 这一过程中调落物基质质量的变化通常会影响参与分解的土壤生物 群落, 可能导致分解过程中土壤动物群落变化特征出现较大的变异性 ${ }^{[8-9]}$ 。首先, 新鲜调落物在分解初期易 分解组分 (如 $\mathrm{N} 、 \mathrm{P}$ ) 含量较高, 可吸引分布广、适应性强、取食新鲜调落物的土壤动物参与调落物的机械破碎, 为微生物的定着创造条件, 因而该阶段土壤动物群落结构较为简 ${ }^{\text {单 }}{ }^{[10]}$ 。其次, 随着调落物质地、基质质量的 改变及微生物群落定着繁衍, 丰富的食物来源和适宜的栖息生境使以植物碎屑和以微生物为食的土壤动物类 群数和个体数显著增加, 它们的参与不仅有利于调落物难分解组分 (如木质素、多酚类物质) 的降解, 而且可 增加土壤食物链的复杂性 ${ }^{[11-12]}$ 。第三, 至调落物分解后期, 调落物基质质量降低, 难分解组分比例和腐殖化 程度不断提高, 不同取食功能类群的土壤动物以及部分稀有类群的参与可能进一步提升碎屑食物链的多样 性 ${ }^{[12-13]}$ 。与此同时, 由于调落物可食性降低, 部分土壤动物类群迁移, 也可能在一定程度上影响土壤动物群 落结构。此外, 不同树种调落物的初始基质质量差异也会对分解过程中土壤动物的数量和群落结构产生影 响 ${ }^{[14]}$ 。然而, 迄今为止关于调落物长期分解过程中土壤动物群落结构变化的关注明显不足。

四川盆地亚热带常绿阔叶林是我国典型的地带性植被分布区。然而,该地区频繁的人类活动干扰致使自 然森林植被受到严重破坏, 正在被大面积的人工林和次生林逐渐取代 ${ }^{[14]}$ 。林分结构的变化可影响凋落物归 
还的数量和质量, 土壤动物群落结构和多样性也可能随之改变, 进而影响调落物分解速率和森林生态系统的 养分循环 ${ }^{[14]}$ 。目前, 对于该区森林土壤动物群落及其生态功能的研究已有不少报道 ${ }^{[8,15-16]}$, 主要集中在植被 更替、氮沉降和调落物分解等方面,并未涉及调落物长期分解过程中土壤动物群落结构变化方面。因此, 以亚 热带典型阔叶树种麻栋 (Quercus acutissima) 和针叶树种柳杉 (Cryptomeria fortunei) 调落叶为对象, 采用分解袋 法开展为期四年的调落叶分解试验, 研究不同树种类型调落叶分解过程中土壤节肢动物群落结构和动态变 化,以期为深人认识森林土壤动物与调落物分解的相互联系与相互作用提供科学参考。

\section{1 材料与方法}

\section{1 研究区域概况}

试验地位于四川省都江堰灵岩山四川农业大学华西雨屏区生态环境监测站 $\left(31^{\circ} 01^{\prime} \mathrm{N}, 103^{\circ} 34^{\prime} \mathrm{E}\right.$, 海拔 $896-1320 \mathrm{~m}$ ), 属亚热带湿润季风气候, 年平均气温 $15.2^{\circ} \mathrm{C}$, 最高气温 ( 7 月) $31.6^{\circ} \mathrm{C}$, 最低气温 $(1$ 月) $-1.4^{\circ} \mathrm{C}$, 年均降雨量约 $1243 \mathrm{~mm}$ 。该区森林以亚热带常绿阔叶林为主, 植物种类繁多, 乔木树种主要有麻栎、 含笑 (Michelia figo)、喜树 (Camptotheca acuminata)、桢楠(Phoebe zhennan)、柳杉等; 林下灌木层主要有光叶海 桐 (Pittosporum glabratum)、胡枝子 (Lespedeza bicolor)、针刺悬钩子 (Rubus pungens) 和十大功劳 (Mahonia fortune) 等; 草本层以扁竹根 (Iris japonica)、麦冬 (Ophiopogon japonicas)、莎草 (Cyperus rotundus) 和芒萁 (Dicranopteris pedata) 等为主。土壤为山地黄壤, 土层厚度 $70 \mathrm{~cm}-100 \mathrm{~cm}, \mathrm{pH} 4.9 \pm 0.3$, 总有机碳 $(19.8 \pm 1.2$ ) $\mathrm{g} / \mathrm{kg}$, 全氮 $(1.4 \pm 0.2) \mathrm{g} / \mathrm{kg}$, 全磷 $(0.9 \pm 0.1) \mathrm{g} / \mathrm{kg}^{[14]}$ 。

1.2 样地设置和样品布设

2010 年 11 月在监测站内设置 1 个面积为 $1 \mathrm{hm}^{2}$ 的监测样地。在样地内 3 条水平线上每隔 $5 \mathrm{~m}$ 安装一个 面积约 $5 \mathrm{~m}^{2}$ 的调落叶收集器,共 15 个,定期收集不同乔木树种调落叶,带回实验室风干后分类。为探讨不同 树种类型 (针叶 vs. 阔叶) 调落叶分解过程中土壤节肢动物群落结构和动态变化, 于 2011 年 10 月调落叶高峰 期后, 将风干的麻栋和柳杉调落叶装人大小为 $20 \mathrm{~cm} \times 20 \mathrm{~cm}$ 调落叶分解袋中, 分解袋表面 (与大气接触面) 孔 径为 $3 \mathrm{~mm}^{[17]}$, 底面 (与土壤接触面) 孔径为 $0.04 \mathrm{~mm}$, 每袋样品的重量为 $(10 \pm 0.05) \mathrm{g}$ 。2011 年 11 月将装袋 好的调落叶分解袋埋置于样地内 5 个 $5 \mathrm{~m} \times 5 \mathrm{~m}$ 样方中, 共埋设调落叶分解袋 130 个 (11 次采样 $\times 5$ 样方 $\times 2$ 树 种+20 备用), 埋设深度与地表调落叶层齐平。分解袋埋置完成后, 随即取 5 袋凋落叶带回实验室, 用以测定 调落叶初始质量特征 (表 1)。分解袋埋设的同时, 分别在调落叶分解袋和样地内距离地面 $1.5 \mathrm{~m}$ 放置纽扣式 温度传感器 (DS1923-F5\#, Maxim/Dallas semiconductor Inc., USA) 连续监测调落物和大气温度 ${ }^{[15]}$ 。传感器 $1 \mathrm{~h}$ 记录 1 次数据每隔 2 月用电脑下载一次数据。

表 1 柳杉和麻栎调落叶初始质量特征 (平均值土标注误差, $n=5$ )

Table 1 Initial quality of leaf litter of Cryptomeria fortunei and Quercus acutissima (Mean $\pm \mathrm{SE}$ )

\begin{tabular}{lccccc}
\hline $\begin{array}{l}\text { 物种 } \\
\text { Species }\end{array}$ & $\begin{array}{c}\text { 碳 Carbon } \\
(\mathrm{C}) /(\mathrm{g} / \mathrm{kg})\end{array}$ & $\begin{array}{c}\text { 氮 Nitrogen } \\
(\mathrm{N}) /(\mathrm{g} / \mathrm{kg})\end{array}$ & $\begin{array}{c}\text { 磷 Phosphorus } \\
(\mathrm{P}) /(\mathrm{g} \mathrm{kg})\end{array}$ & $\begin{array}{c}\text { 木质素 Lignin } \\
(\mathrm{L}) / \%\end{array}$ & $\begin{array}{c}\text { 纤维素 Cellulose } \\
(\mathrm{CL}) / \%\end{array}$ \\
\hline 柳杉 Cryptomeria fortunei & $480.73 \pm 20.34$ & $10.66 \pm 0.48^{*}$ & $0.85 \pm 0.07$ & $19.58 \pm 0.60^{*}$ & $19.32 \pm 0.31^{*}$ \\
麻栋 Quercus acutissima & $490.49 \pm 24.13$ & $13.23 \pm 0.70$ & $0.92 \pm 0.05$ & $24.05 \pm 0.09$ & $14.90 \pm 0.61$ \\
\hline \hline 物种 & 碳/氮 & 碳/磷 & 氮/磷 & 木质素/氮 & 木质素/纤维素 \\
Species & $\mathrm{C} / \mathrm{N}$ & $\mathrm{C} / \mathrm{P}$ & $\mathrm{N} / \mathrm{P}$ & $\mathrm{L} / \mathrm{CL}$ & $1.01 \pm 0.01^{*}$ \\
\hline 柳杉 Cryptomeria fortunei & $45.10 \pm 0.39^{*}$ & $567.52 \pm 22.06^{*}$ & $12.58 \pm 0.44^{*}$ & $1.84 \pm 0.04$ & $1.82 \pm 0.09$ \\
麻栋 Quercus acutissima & $37.07 \pm 0.66$ & $536.26 \pm 9.64$ & $14.47 \pm 0.33$ & & $1.62 \pm 0.05$ \\
\hline
\end{tabular}

* 上标表示在 $P<0.05$ 水平上差异显著 $(P<0.05)$

\section{3 样品采集与土壤动物分离}

样品采集于 2011 年 12 月 27 日、 2012 年 4 月 27 日、 8 月 25 日、 12 月 26 日、 2013 年 4 月 24 日、 8 月 13 日、 12 月 27 日、 2014 年 4 月 27 日、 10 月 26 日、 2015 年 4 月 24 日和 10 月 26 日进行,共 11 次采样,与之对应的调 
落叶分解阶段为 $35 \mathrm{~d} 、 156 \mathrm{~d} 、 277 \mathrm{~d} 、 398 \mathrm{~d} 、 516 \mathrm{~d} 、 628 \mathrm{~d} 、 746 \mathrm{~d} 、 896 \mathrm{~d} 、 1079 \mathrm{~d} 、 1261 \mathrm{~d} 、 1444 \mathrm{~d}$ 。采样时, 从每个 样方中采集分解袋 2 袋, 将分解袋装人透气的黑布袋中低温保存, $12 \mathrm{~h}$ 内带回实验室。采用 Tullgren 漏斗 (4 mm) 分离收集的土壤节肢动物, 分离周期为 $48 \mathrm{~h}$ 。采用体式解剖镜和生物显微镜镜检计数和分类, 参考 《中国土壤动物检索图鉴》 ${ }^{[17]}$ 《昆虫分类检索》 ${ }^{[18]}$ 鉴定到科水平。

\section{4 数据统计与分析}

根据捕获个体数量占捕获总量百分比,将个体数量 $10.0 \%$ 以上的类群划分为优势类群, $1.0 \%-10.0 \%$ 的类群 划分为常见类群,小于 $1.0 \%$ 的类群划分为稀有类群 ${ }^{[17]}$ 。由于土壤动物区系种类繁多、食性和营养级类型复杂多 样,且取食食性易随季节和生境条件变化,将其系统分类为某一特定的功能类群难度较大。因此,基于已有的文 献资料和各类群的总体特征将捕获的土壤动物划分为捕食性、植食性、菌食性、腐食性四个功能类群 ${ }^{[14,19]}$ 。

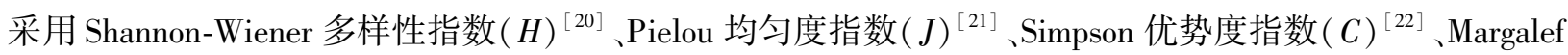
丰富度指数 $(D)^{[23-24]}$ 计算残留调落物中土壤动物群落多样性随分解进程的变化特征,计算公式如下:

$$
\begin{aligned}
& H=-\sum_{i=1}^{s} P_{i} \cdot \operatorname{In} P_{i} \\
& J=H / \ln S \\
& C=\sum\left(n_{i} / N\right)^{2} \\
& D=(S-1) / \ln N
\end{aligned}
$$

式中, $S$ 为土壤动物群落的类群数; $P_{i}=n_{i} / N, n_{i}$ 为每个类群的个体数, $N$ 为总的个体数。

独立样本 $\mathrm{T}$ 检验 (Student's independent-sample t-test) 调落叶初始基质质量以及同一采样时期两个树种调 落叶土壤节肢动物个体密度、类群数量和多样性指数的差异; 重复方差分析 (repeated measures ANOVA) 检验 调落叶树种、采样时间及其交互作用对土壤节肢动物群落特征的影响,统计分析由 IBM SPSS 22.0( IBM SPSS Statistics, Chicago, IL, USA) 完成。采用 Cluster 聚类和非度量多维尺度方法 (non-metric multidimensional scaling analysis) 对比两种调落叶土壤节肢动物群落结构, 检验分析由 R 软件( version 3.5.2) 完成。

\section{2 结果}

\section{1 土壤节肢动物组成随调落叶分解的变化特征}

整个分解期间, 共捕获土壤节肢动物 3855 只,隶属 16 目 51 科 (表 2 和表 3 ), 其中麻栋凋落叶中 1924 只, 柳杉调落叶中 1931 只。2 种调落叶中土壤节肢动物的优势类群均为弹尾目, 麻栋调落叶以等节跳科 (Isotomidae) 和棘跳科 (Onychiuriclae) 为优势类群,柳杉调落叶以等节跳科,棘跳科和圆跳科 (Sminthuridae) 为 优势类群; 它们共有的常见类群有隐翅甲科 (Staphylinidae)、摇蚊科 (Chironomidae) 、土革螨科 (Ologamasidae)、蚁科 (Formicidae) 等 10 科, 稀有类群有蚁甲科 (Pselaphidae)、长角毛蚊科幼虫 (Hesperinidae)、爪跳科 (Paronellidae)、三甲螨科 (Oribotritiidae)、原铗虫八科 (Projapygidae) 等 14 科。稀有类 群长须螨科 (Stigmaeidae)、赤螨科 (Erythraeidae)、隐颚螨科 (Cryptognathidae) 等 8 科仅在麻栋调落叶中检出, 长角跳科 (Entomobryidae)、罗甲螨科 (Lohmanniidae)、狼蛛科 (Lycosidae) 等 11 科只在柳杉调落叶中捕获。

调落叶分解袋埋设后, 土壤节肢动物快速定殖, 个体密度和类群数量随调落叶分解进程不断变化 (图 1)。 麻栋调落叶土壤节肢动物的个体密度随分解进程呈现增加趋势, 在分解的 $1079 \mathrm{~d}$ 达最高值后降低; 而柳杉调 落叶则在分解的 $156 \mathrm{~d}$ 急剧增加后快速降低。2 类树种调落叶土壤节肢动物类群数量具有相似的动态变化过 程, 但麻栎调落叶土壤节肢动物类群数量显著高于柳杉调落叶, 麻栋和柳杉调落叶土壤节肢动物类群数量分 别在分解的 $746 \mathrm{~d}$ 和 $1079 \mathrm{~d}$ 达到最高值。调落叶种类、分解时间及其交互作用均显著影响土壤节肢动物的个 体密度和类群数量。整个分解阶段, 麻栋凋落叶土壤节肢动物总体上以常见类群占比最高, 而柳杉调落叶土 壤节肢动物以优势类群占比最大 (图 2)。柳杉调落叶中稀有类群占比高于麻栋调落叶, 且随着分解进程, 柳 杉调落叶中优势类群占比呈现上升趋势。 


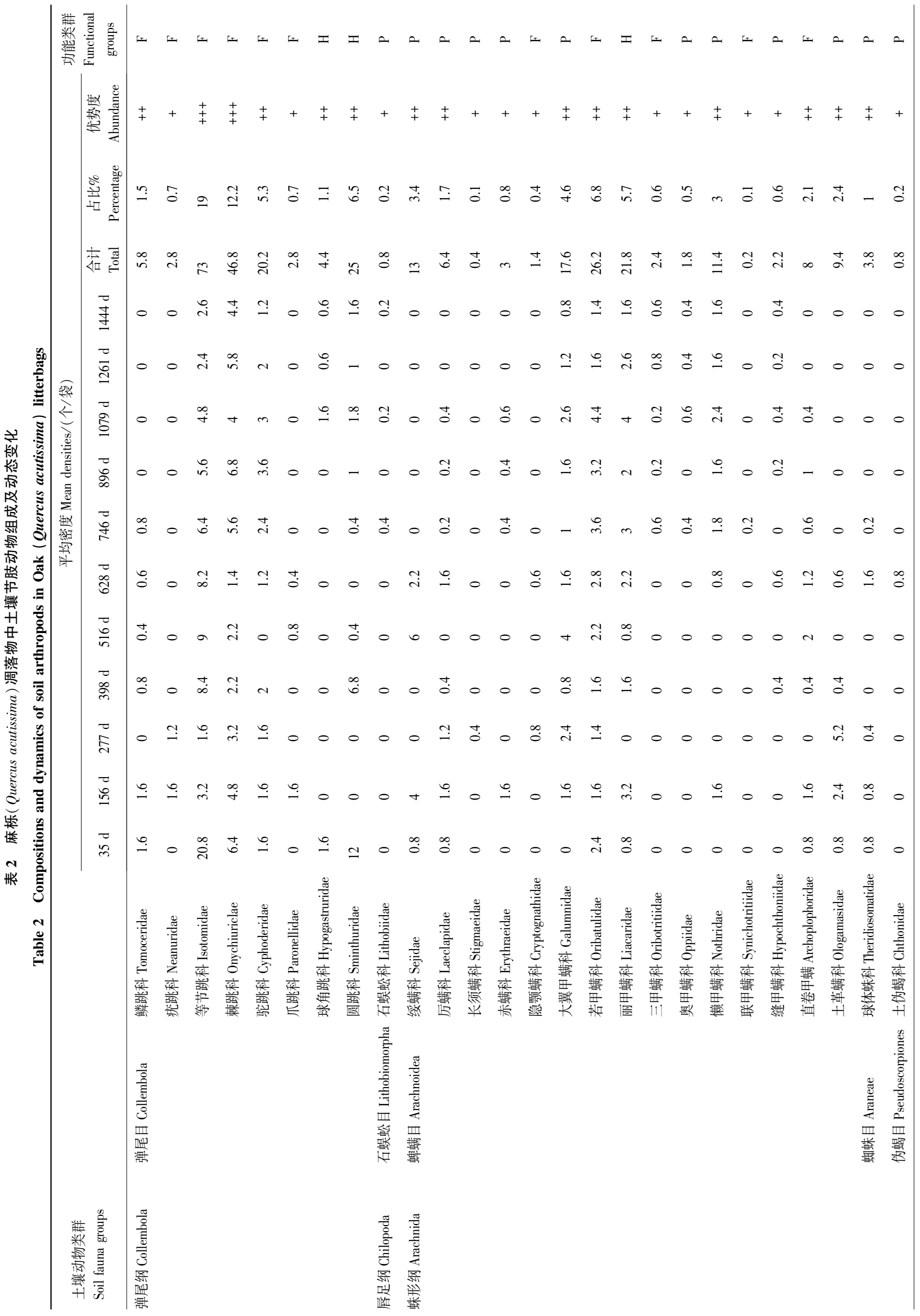

http://www.ecologica.cn 


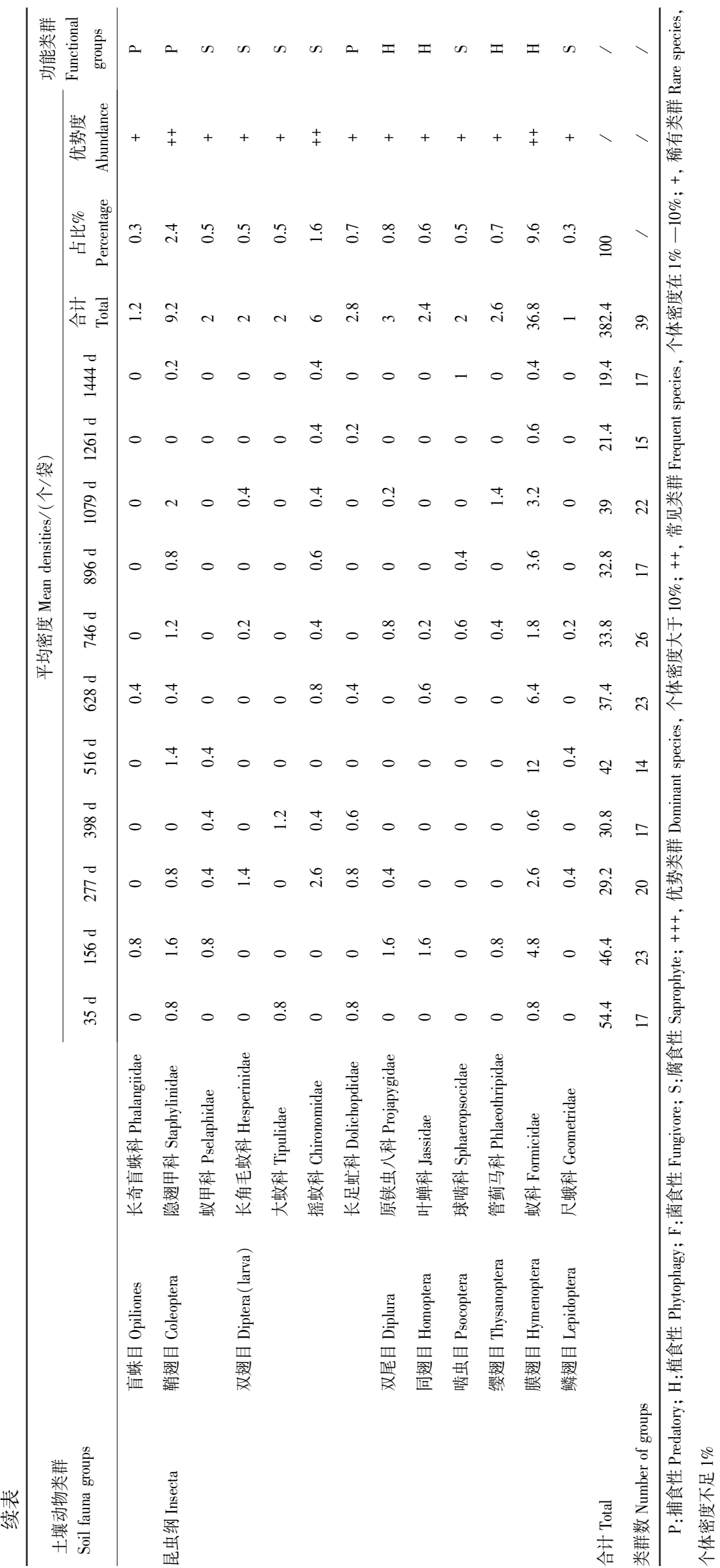




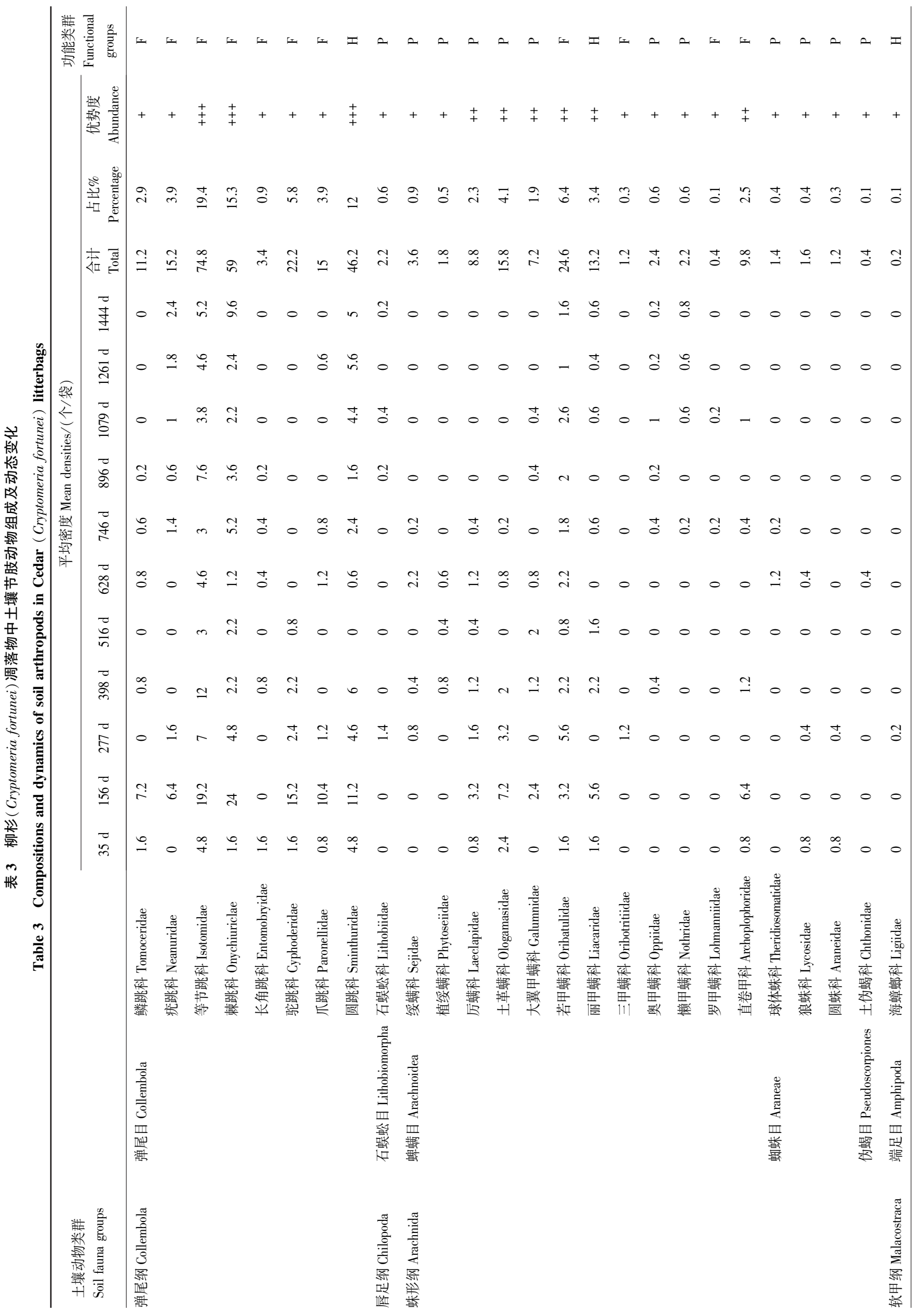




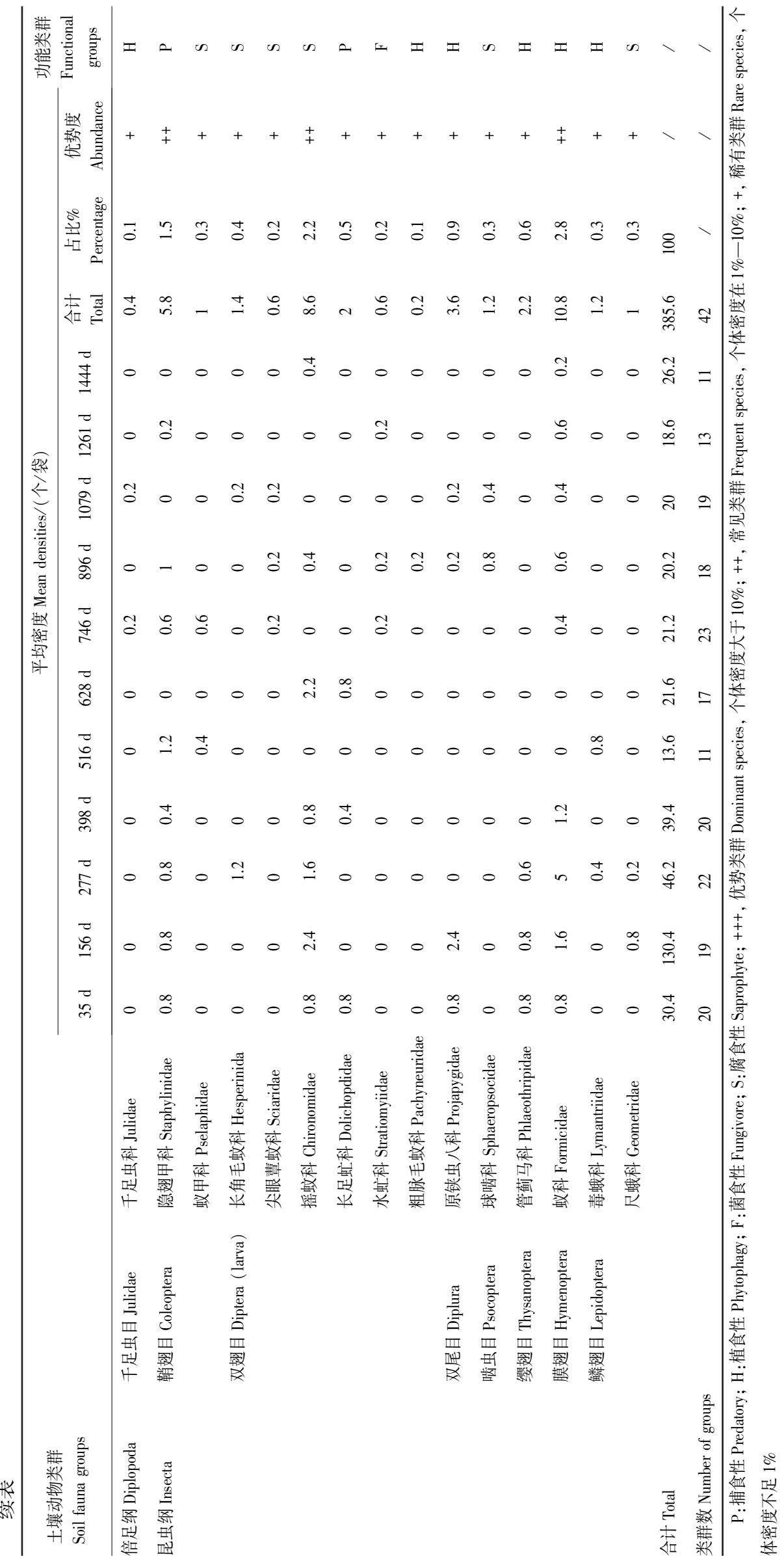

http ://www.ecologica.cn 


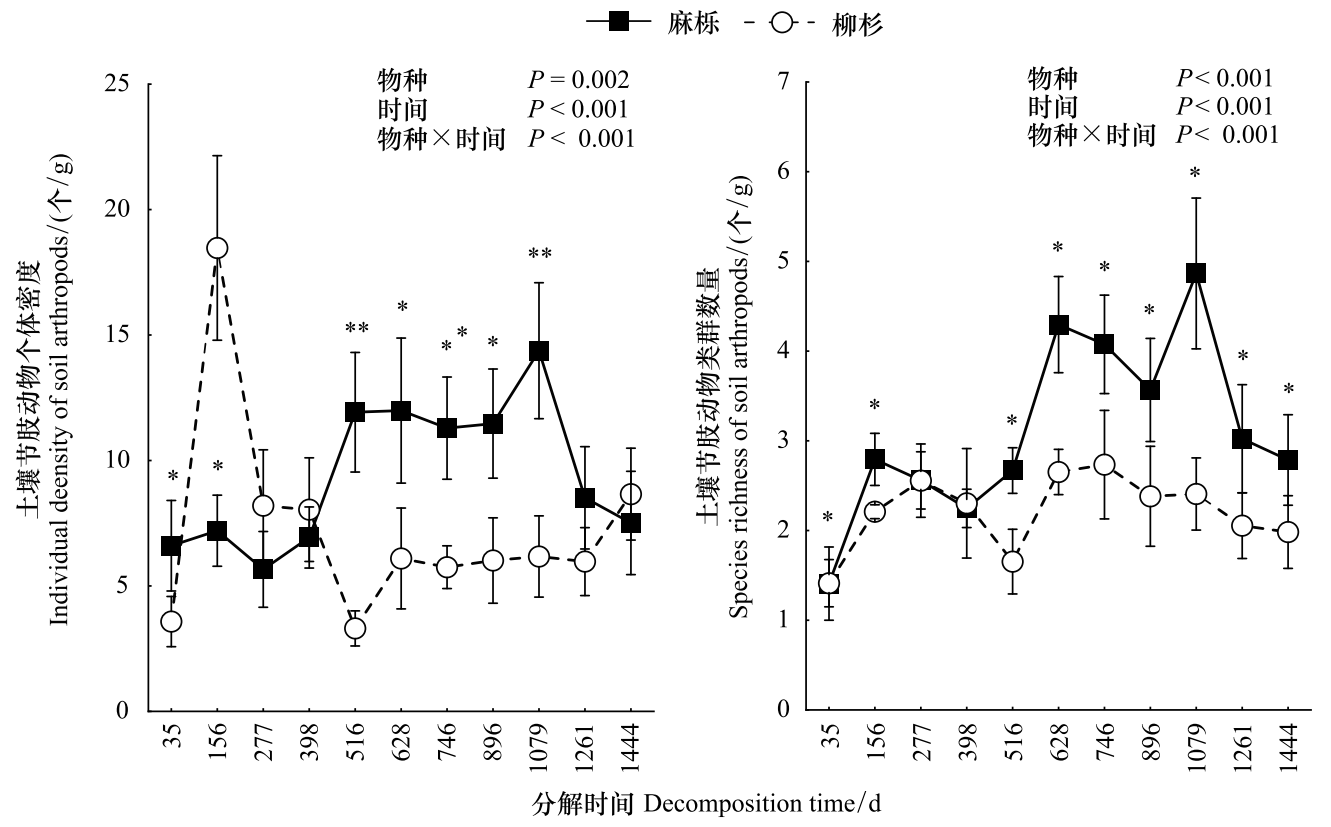

图 1 麻栋和柳杉调落叶分解过程中土壤节肢动物个体密度和类群数量动态 ( 平均值土标准误, $n=5$ )

Fig.1 Dynamics of individual density and species richness of soil arthropods (Mean $\pm \mathrm{SE}, n=5)$ in the Oak (Quercus acutissima) and Cedar (Cryptomeria fortunei) litterbags during litter decomposition $(*, P<0.05, * *, P<0.01)$

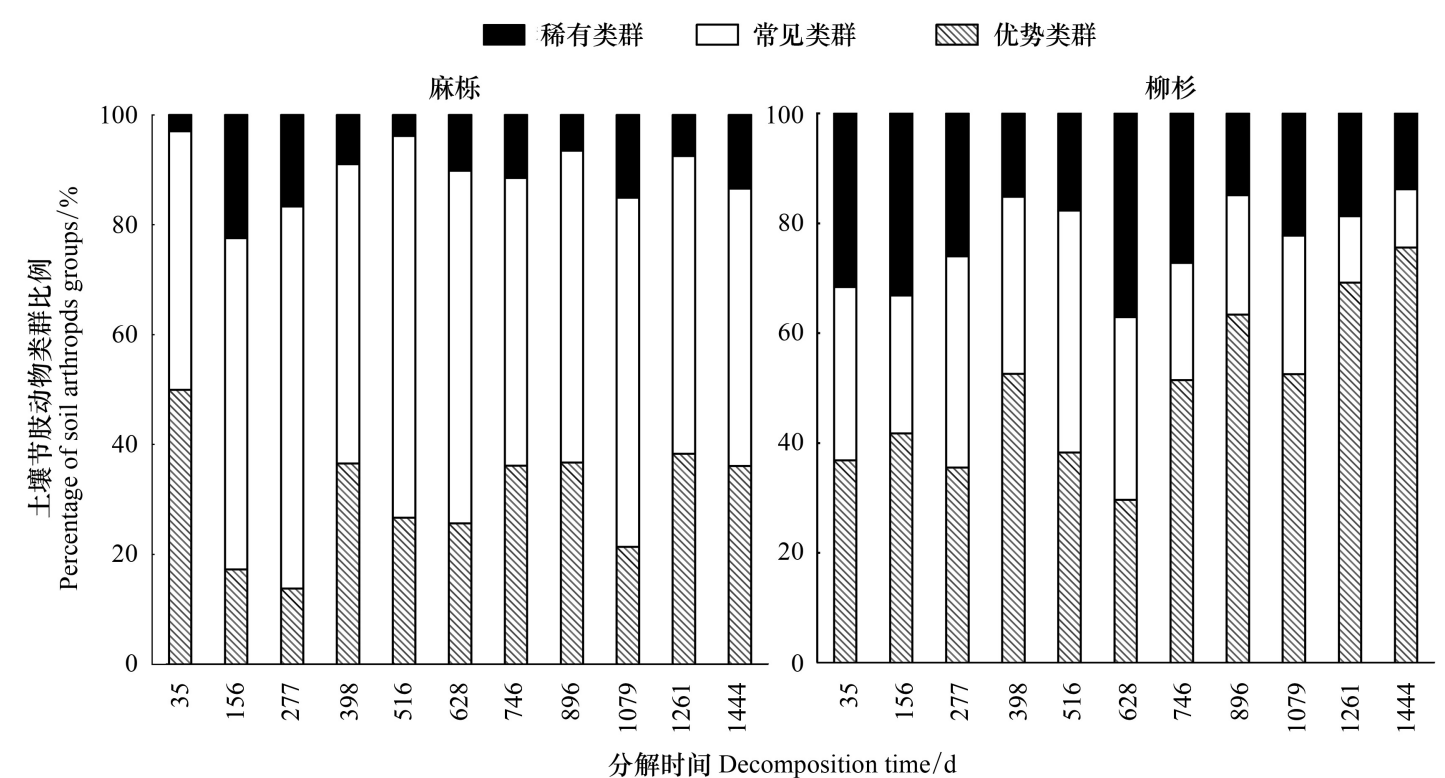

图 2 麻栎和柳杉调落叶分解过程中土壤节肢动物类群 ( 优势类群、常见类群、稀有类群) 动态 (平均值土标准误, $n=5$ )

Fig.2 Dynamics of soil arthropods groups (dominant species, frequent species and rare species) (Mean $\pm \mathrm{SE}, n=5)$ in the Oak (Quercus acutissima) and Cedar (Cryptomeria fortunei) litterbags during litter decomposition

2.2 土壤节肢动物功能类群随调落叶分解的变化特征

土壤节肢动物功能类群随凋落叶类型和分解进程变化明显不同 (图 3)。两种凋落叶中捕获的土壤节肢 动物以菌食性占比最高, 腐食性最低, 且随调落叶分解进程, 植食性土壤节肢动物占比明显下降, 菌食性则上 升。在麻栋调落叶分解过程中, 捕食性土壤节肢动物比例仅在 $277 \mathrm{~d}$ 有明显降低,植食性土壤节肢动物在分 解的 $277 \mathrm{~d}$ 数量占比最大。柳杉调落叶分解过程中, 捕食性土壤节肢动物占比明显波动, 在分解的 $628 \mathrm{~d}$ 占比 
最低,与之相反植食性土壤节肢动物占比在分解的 $628 \mathrm{~d}$ 增至最大值后明显降低。

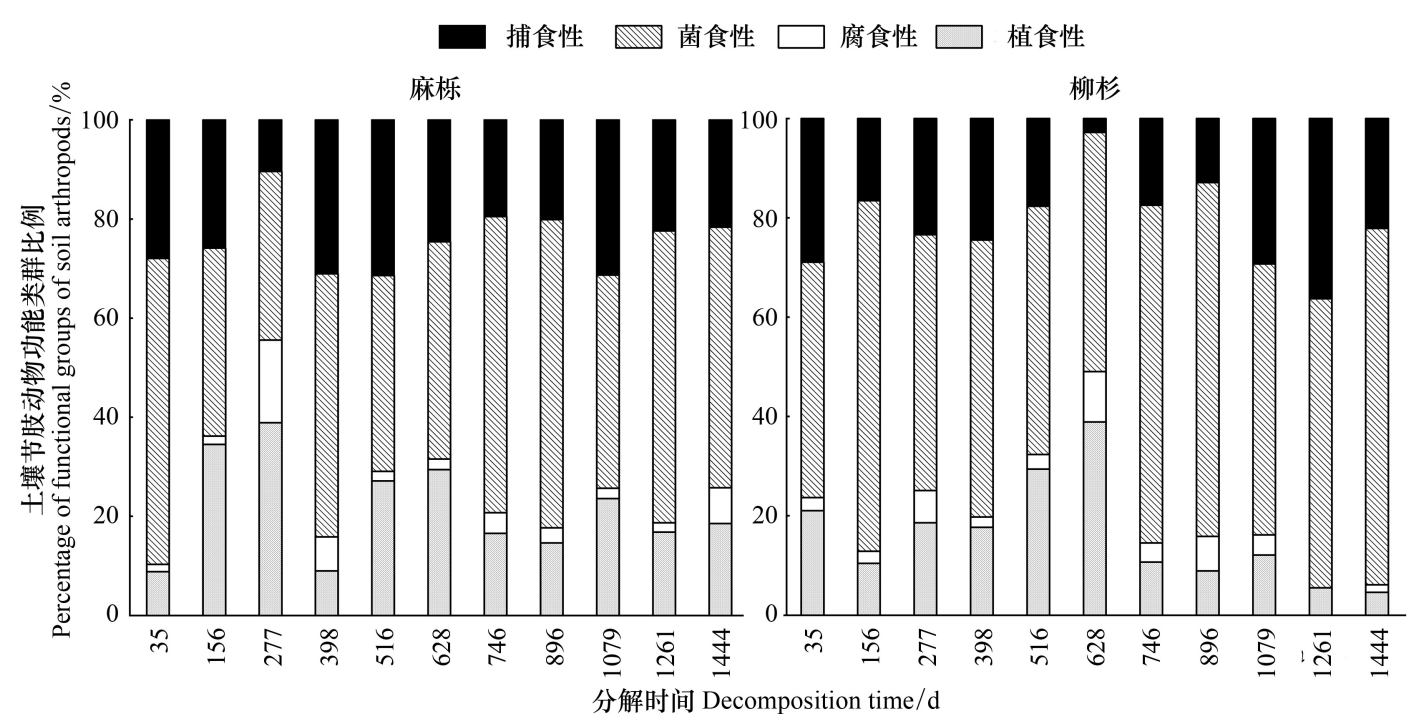

图 3 麻柇和柳杉调落叶分解过程中土壤节肢动物功能类群 ( 捕食性、菌食性、腐食性和植食性) 动态 (平均值 \pm 标准误, $n=5$ )

Fig.3 Dynamics of functional groups of soil arthropods ( predatorse, fungivore, saprophyt and phytophaga) (Mean \pm SE, $n=5)$ in the Oak

(Quercus acutissima) and Cedar (Cryptomeria fortunei) litterbags during litter decomposition

\section{3 土壤节肢动物多样性随调落叶分解的变化特征}

由图 4 可见,两种调落叶分解过程中土壤节肢动物多样性总体呈现出相似的动态变化。除均匀度指数 外, 2 种调落叶土壤节肢动物优势度、多样性和丰富度指数差异显著 $(P<0.05)$ 。在多数时期,柳杉调落叶中捕 获的土壤节肢动物优势度指数大于麻栋, 总体呈上升趋势, 多样性指数与丰富度指数都呈现下降趋势, 且多数 时期麻栎大于柳杉,均匀度变化波动不大。非度量多维尺度 (NMDS) 分析表明,两种调落叶土壤节肢动物群 落组成具有显著差异 $(P=0.02)$, 聚类分析显示, 两种调落叶土壤节肢动物群落结构随分解进程相似性不断降 低(图 5)。

\section{3 讨论}

土壤动物通过取食、破碎、搬运等方式参与调落物分解, 是构成凋落物分解速率变异的重要生物因素 ${ }^{[25]}$ 。 研究表明,土壤动物群落空间自相关性随类群和生境不同,其组成和结构随调落物类型和基质质量变化而 异 ${ }^{[26]}$ 。本研究中, 柳杉和麻栎凋落叶分解袋中捕获的土壤节肢动物总数量无显著差异, 土壤节肢动物类群组 成与我国亚热带/热带森林研究结果较为相似 ${ }^{[27-28]}$ 。整个研究期间, 捕获土壤节肢动物以蜱螨目和弹尾目为 优势类群 (表 2 和表 3 ), 这与易兰等 ${ }^{[29]}$ 在亚热带森林中的研究结果一致, 这是由于它们取食真菌、细菌以及 植物调落物碎屑, 少部分也可以捕食其他小型土壤动物, 食性相对复杂的原因 ${ }^{[30]}$ 。2 种调落叶中捕获的土壤 节肢动物个体密度和类群数量随分解时期不同差异显著, 麻栎调落叶的土壤节肢动物个体密度和类群数量在 分解后期显著高于柳杉, 这与短期调落物分解的研究结果存在不一致性 ${ }^{[10,31]}$ 。通常, 针叶调落物的 $\mathrm{C} / \mathrm{N}$ 、 Lignin/ $\mathrm{N}$ 、萜类及酚类物质含量比阔叶调落物高, 这种调落物基质质量会降低了自身的分解速率, 也会限制土 壤动物群落在调落物中的生长和繁衍 ${ }^{[17,32-33]}$ 。同时, Bradford 等 ${ }^{[34]}$ 研究指出, $\mathrm{C} / \mathrm{N}$ 值是决定调落叶分解速率 及参与分解土壤生物丰度的重要因子。与麻栋调落叶基质质量相比,柳杉调落叶高的 $\mathrm{C} / \mathrm{N}$ 值可能是造成参 与凋落物分解土壤节肢动物密度和类群数量降低的原因 (表 1)。值得注意的是, 两种调落叶获得的优势类群 和常见类群相似度较高, 但稀有类群差异较大, 如赤螨科、球角跳科、叶蝉科仅在麻栋凋落叶中出现, 长角跳 科、罗甲螨科、海蟑螈科仅出现在柳杉调落叶中。这是因为不同稀有类群土壤动物取食特性和获得食物源不 


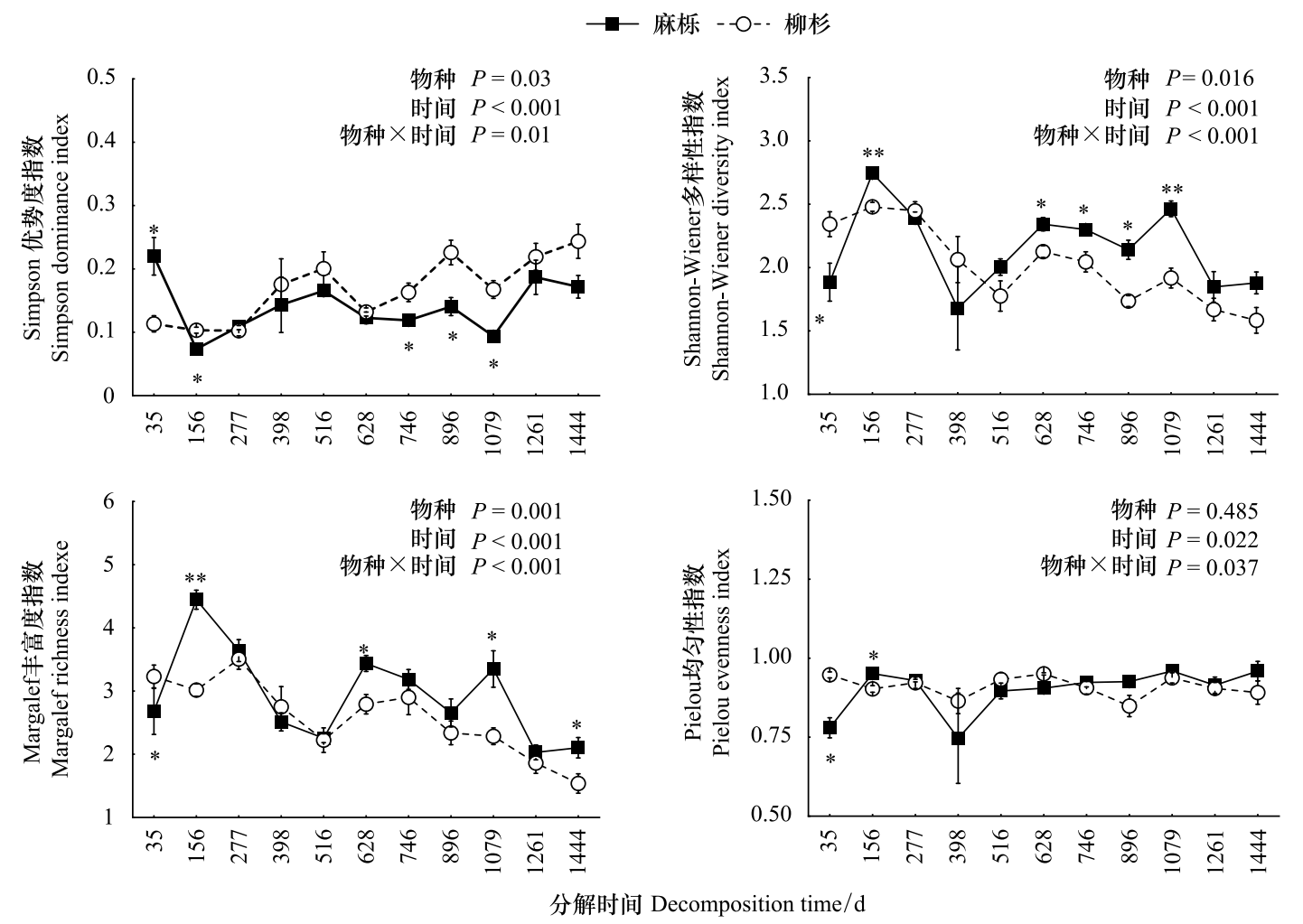

图 4 麻栎和柳杉调落叶分解过程中土壤节肢动物多样性指数动态 (平均值 \pm 标准误, $n=5$ )

Fig.4 Dynamics of diversity index of soil arthropods ( $\mathrm{Mean} \pm \mathrm{SE}, n=5)$ in the Oak (Quercus acutissima) and Cedar (Cryptomeria fortunei) litterbags during litter decomposition $(*, P<0.05, * *, P<0.01)$
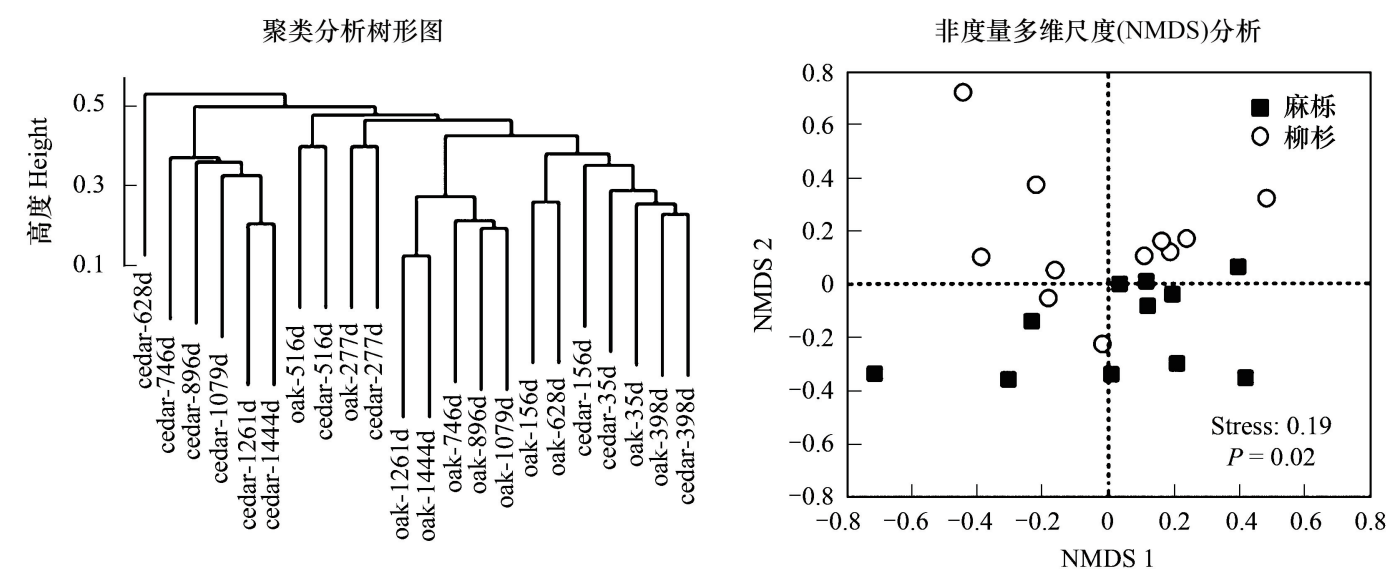

图 5 麻栎和柳杉调落叶分解过程中土壤节肢动物组成 Cluster 聚类和非度量多维尺度 (NMDS) 分析

Fig.5 Grouping average clustering and non-metric multidimensional scaling (NMDS) of soil arthropods composition in the Oak (Quercus acutissima) and Cedar (Cryptomeria fortunei) litterbags during litter decomposition

同的原因,而分解过程中食物源和调落叶基质特性变化也会导致稀有类群组成和数量的变化。

不同土壤动物类群的体形大小和活动能力相差悬殊,但它们在土壤生态系统中常常占据着相同的生态 位 ${ }^{[19]}$, 所以目前还无法将所有土壤动物类群的生态习性细化分类, 而是按各类群的总体特征将土壤动物划分 成不同的营养级, 如本研究中的腐食性、植食性、菌食性和捕食性 ${ }^{[19,35]}$ 。已有的研究表明 ${ }^{[12,29]}$, 土壤动物功能 
类群在调落叶分解初期以菌食性为主, 中期以植食性和菌食性为主, 后期食物链和功能类群复杂化,将导致捕 食性和腐食性类群的增加。这在本研究中也得到较好的证实, 两种调落叶分解过程中土壤节肢动物功能类群 总体以菌食性为主, 其次是捕食性和植食性, 腐食性最少 (图 3)。同时, 植食性土壤节肢动物比例在麻係调落 叶分解初期 (35-277 d) 迅速上升,而其在柳杉凋落叶中至分解的 $516 \mathrm{~d}$ 才显著增加,这与王小平等 ${ }^{[36]}$ 的短期 研究结果不一致。麻栋调落叶质地柔软, 初始养分含量高等特征更易于植食性土壤节肢动物快速定着, 使得 土壤动物的破碎作用在分解前期就开始发挥作用 ${ }^{[37]}$ 。相比之下, 柳杉调落叶的针叶表面革质,角质层发达, 且含有较多难分解物质 (木质素、纤维素、单宁等), 阻碍了微生物和土壤动物的定着和繁殖 ${ }^{[35]}$, 且淋溶作用 也不及阔叶, 所以土壤动物前期的取食破碎作用在 $35 \mathrm{~d}$ 后开始受到限制, 植食性类群在分解中期才开始大量 出现。

物种多样性指标能反应群落组成的复杂程度以及群落稳定性 ${ }^{[31]}$ 。本研究发现, 调落叶长期分解过程中, 树种、时间及两者的交互作用对调落叶中捕获的土壤节肢动物多样性指数、优势度和丰富度指数影响显著。 丰富度指数是表征土壤生境优越与否的参数 ${ }^{[28]}$, 在两个树种间该指数存在明显差异, 说明两者分解过程中的 微生境条件差异较大。在柳杉和麻栎调落叶分解过程中, 土壤节肢动物丰富度指数总体呈现下降趋势, 但个 别分解时期 (如分解的 $156 \mathrm{~d}, 628 \mathrm{~d}$ 和 $1261 \mathrm{~d}$ ) 柳杉调落叶丰富度指数显著低于麻栎调落叶, 与类群密度变化 一致。这主要是针叶调落物在分解初期速率缓慢, 土壤动物类群种类较少, 且主要以菌食性为主的原因。多 样性指数和均匀度的高低可以体现生态系统食物链长短和共生现象的多少, 从而分析该生态系统群落结构的 稳定性 ${ }^{[38]}$ 。本研究中, 不同树种间土壤节肢动物多样性指数的差异主要集中在分解后期, 柳杉叶土壤节肢动 物的多样性指数在分解一年后迅速降低, 这与短期的研究结果明显不同 ${ }^{[39]}$ 。而非度量多维尺度 (NMDS) 和 聚类分析显示, 两种调落叶土壤节肢动物群落组成和结构在分解过程中具有显著差异, 相似程度随分解进程 不断降低 (图 5)。这种土壤动物组成和结构在分解过程中的差异可能是造成不同物种或类型调落叶分解速 率变异的重要因素。值得注意的是, 土壤节肢动物的均匀性指数在两种调落叶中差异不显著, 说明两类树种 土壤动物群落结构的稳定性表现较为一致。此外,优势度指数是在群落类群组成基础上进一步推算出来以表 达群落组成状况的指标, 优势度指数高就表明群落内不同类群的分布越不均匀, 相比之下, 优势类群就更能发 挥自身的生态功能 ${ }^{[40]}$ 。柳杉调落叶的土壤节肢动物优势度在分解过程中逐渐增加, 这与柳杉的优势类群占 比变化一致, 但与短期的研究相比 ${ }^{[14]}$, 两类调落叶的优势度总体较低, 表明研究区域土壤节肢动物优势类群 的生态功能可能未得到充分发挥, 针叶调落物的降解可能更加依赖某些特定土壤动物类群的作用。

综上所述, 土壤节肢动物群落的组成和结构随调落叶分解过程不断变化, 且与短期分解的研究结果存在 明显差异。土壤节肢动物的稀有类群组成、群落结构和多样性因调落叶类型和基质质量差异而不同。这些结 果表明调落物分解过程中土壤动物的群落结构和多样性与调落物类型密切相关, 土壤动物群落结构差异是构 成不同类型调落物分解速率差异的重要生物因素。

\section{参考文献 ( References) :}

[ 1 ] Wardle D A, Bardgett R D, Klironomos J N, Setala H, Van Der Putten W H, Wall D H. Ecological linkages between aboveground and belowground biota. Science, 2004, 304(5677) : 1629-1633.

[ 2 ] Potapov A M, Tiunov A V, Scheu S. Uncovering trophic positions and food resources of soil animals using bulk natural stable isotope composition. Biological Reviews, 2019, 94(1): 37-59.

[ 3 ] 梁文举, 闻大中. 土壤生物及其对土壤生态学发展的影响. 应用生态学报, 2001, 12(1): 137-140.

[ 4 ] 殷秀琴, 宋博, 邱丽丽. 红松阔叶混交林凋落物-土壤动物-土壤系统中 $\mathrm{N} 、 \mathrm{P} 、 \mathrm{~K}$ 的动态特征. 生态学报, 2007, 27(1)：128-134.

[ 5 ] Meyer III W M, Ostertag R, Cowie R H. Macro-invertebrates accelerate litter decomposition and nutrient release in a Hawaiian rainforest. Soil Biology and Biochemistry, 2011, 43(1): 206-211.

[ 6 ] Wolters V. Invertebrate control of soil organic matter stability. Biology and Fertility of Soils, 2000, 31(1): 1- 19.

[ 7 ] Huhta V. The role of soil fauna in ecosystems: a historical review. Pedobiologia, 2007, 50(6) : 489-495.

[ 8 ] 吴福忠, 谭波. 森林调落物分解过程与土壤动物的相互关系研究进展. 四川农业大学学报, 2018, 36(5): 569-575. 
[ 9 ] Huang W, González G, Zou X M. Earthworm abundance and functional group diversity regulate plant litter decay and soil organic carbon level: a global meta-analysis. Applied Soil Ecology, 2020, 150: 103473.

[10] 龙健, 张明江, 赵畅, 吴求生, 吴劲楠, 黄博聪, 张菊梅. 土壤动物对茂兰喀斯特森林调落物分解过程中元素释放的作用. 生态学杂志, 2019, 38(9): 2671-2682.

[11] Bray S R, Kitajima K, Mack M C. Temporal dynamics of microbial communities on decomposing leaf litter of 10 plant species in relation to decomposition rate. Soil Biology and Biochemistry, 2012, 49: 30-37.

[12] 徐璇, 王维枫, 阮宏华. 土壤动物对森林凋落物分解的影响: 机制和模拟. 生态学杂志, 2019, 38(9): 2858-2865.

[13] 王文君, 杨万勤, 谭波, 刘瑞龙, 吴福忠. 四川盆地亚热带常绿阔叶林不同物候期调落物分解与土壤动物群落结构的关系. 生态学报, $2013,33(18): 5737-5750$

[14] Tan B, Wu F Z, Yang W Q, Wang A, Yang Y L. Soil fauna community dynamics during soil thawing period in the subalpine and alpine forests of western china. Polish Journal of Ecology, 2012, 60(4) : 755-766.

[15] 王文君, 杨万勤, 谭波, 刘瑞龙, 吴福忠. 四川盆地亚热带常绿阔叶林土壤动物对几种典型调落物分解的影响. 生态环境学报, 2013,22 (9) : 1488-1495.

[16] 徐国良, 莫江明, 周国逸, 薛璟花. 氮沉降下鼎湖山森林调落物分解及与土壤动物的关系. 生态环境, 2005, 14(6): 901-907.

[17] 尹文英, 胡圣豪, 沈暳芬, 宁应之, 孙希达, 吴纪华, 诸葛燕, 张云美, 王敏, 陈建英, 徐成纲, 梁彦龄, 王洪铸, 杨潼, 陈德牛, 张国庆, 宋大祥, 陈军. 中国土壤动物检索图鉴. 北京: 科学出版社, 1998.

［18］李鸿兴, 隋敬之, 周士秀, 周勤, 孙洪国. 昆虫分类检索. 北京: 农业出版社, 1987.

[19］黄丽荣, 张雪萍. 大兴安岭北部森林生态系统土壤动物的功能类群及其生态分布. 土壤通报, 2008，39(5)：1017-1022.

[20] Shannon C E, Weaver W. The Mathematical Theory of Communication. Urbana: University of Illinois Press, 1949 : $117-117$.

[21] Pielou E C. Ecological Diversity. New York: Wiley, 1975.

[22] Simpson E H. Measurement of diversity. Nature, 1949, 163: 688.

[23］马克平. 生物群落多样性的测度方法 I. $\alpha$ 多样性的测度方法(上). 生物多样性, 1994, 2(3): 162-168.

[24] 马克平, 刘玉明. 生物群落多样性的测度方法 I. $\alpha$ 多样性的测度方法(下). 生物多样性, 1994, 2(4): 231-239.

[25] Aerts R. Climate, leaf litter chemistry and leaf litter decomposition in terrestrial ecosystems: a triangular relationship. Oikos, 1997, 79( 3 ) : 439- 449 .

[26] 高梅香, 林琳, 常亮, 孙新, 刘冬, 吴东辉. 土壤动物群落空间格局和构建机制研究进展. 生物多样性, 2018, 26( 10) : 1034-1050.

[27] 尹文英. 中国亚热带土壤动物. 北京: 科学出版社, 1992.

[28] 廖崇惠, 李健雄, 杨悦屏, 张振才. 海南尖峰岭热带林土壤动物群落——群落的组成及其特征. 生态学报, 2002, 22( 11): 1866-1872.

[29] 易兰, 由文辉, 宋永昌. 天童常绿阔叶林五个演替阶段凋落物中的土壤动物群落. 生态学报, 2005, 25(3): 466-473.

[30］郡元虎, 张卫信, 刘胜杰, 王晓丽, 傅声雷. 土壤动物多样性及其生态功能. 生态学报, 2015, 35(20): 6614-6625.

[31] 刘瑞龙, 杨万勤, 吴福忠, 谭波, 王文君. 川西亚高山/高山森林调落物分解过程中土壤动物群落结构及其多样性动态. 应用与环境生物 学报, 2014, 20(3): 499-507.

[32] Zhang P, Tian X J, He X B, Song F Q, Ren L L, Jiang P. Effect of litter quality on its decomposition in broadleaf and coniferous forest. European Journal of Soil Biology, 2008, 44(4) : 392-399.

[33] Xiao W Y, Chen H Y H, Kumar P, Chen C, Guan Q W. Multiple interactions between tree composition and diversity and microbial diversity underly litter decomposition. Geoderma, 2019, 341: 161-171.

[34] Bradford M A, Berg B, Maynard D S, Wieder W R, Wood S A. Understanding the dominant controls on litter decomposition. Journal of Ecology, 2016, 104(1): 229-238.

[35] Navarro-Campos C, Pekas A, Moraza M L, Aguilar A, Garcia-Marí F. Soil-dwelling predatory mites in citrus: Their potential as natural enemies of thrips with special reference to Pezothrips kellyanus (Thysanoptera: Thripidae). Biological Control, 2012, 63(2) : 201-209.

[36] 王小平, 杨雪, 杨楠, 辛晓静, 曲耀冰, 赵念席, 高玉葆. 凋落物多样性及组成对凋落物分解和土壤微生物群落的影响. 生态学报, 2019, $39(17): 6264-6272$

[37］郭剑芬, 杨玉盛, 陈光水, 林鹏, 谢锦升. 森林调落物分解研究进展. 林业科学, 2006, 42(4): 93-100.

[38］刘新民, 门丽娜. 内蒙古武川县农田退耕还草对大型土壤动物群落的影响. 应用生态学报, 2009, 20(8)：1965-1972.

[39] 熊燕, 刘强, 陈欢, 彭少麟. 鼎湖山季风常绿阔叶林调落叶分解与土壤动物群落动态和多样性. 生态学杂志, 2005, 24(10): 1120-1126.

[40] 崔丽巍, 刘世荣, 刘兴良, 吴鹏飞, 张洪芝, 何先进. 川西北冷杉林恢复过程中土壤动物群落动态. 生态学报, 2012, 32 (15): 4772-4783. 